\title{
Mathematics teacher preparation examined in an international context: learning from the Teacher Education and Development Study in Mathematics (TEDS-M) and beyond
}

\author{
Yeping Li
}

Accepted: 7 May 2012/Published online: 19 May 2012

(c) FIZ Karlsruhe 2012

This thematic issue contains a collection of papers that resulted from the recent Teacher Education and Development Study in Mathematics (TEDS-M), a study that is the first large-scale international comparative study on mathematics teacher preparation undertaken under the auspices of the International Association for the Evaluation of Educational Achievement (IEA). The significance of TEDS-M itself has been well articulated by different authors in this thematic issue. As the importance of teachers and teaching has been commonly acknowledged for the improvement of students' achievement in school mathematics (e.g., Sowder 2007), it becomes apparent that we need to examine and understand possible influences of system policy and institutional practices on the outcomes of mathematics teacher preparation both within an education system (e.g., Wilson, Floden, and Ferrini-Mundy 2001) and in an international context (e.g., Leung and Li 2010).

The contributions of this thematic issue build upon TEDS-M, including several reports of selected findings from that study. Moreover, this thematic issue goes above and beyond direct reporting of TEDS-M, and includes unique contributions with different natures. To make these contributions explicit, I will highlight some of them as follows.

1. This thematic issue highlights international collaborative efforts in conceptualizing and examining mathematics teachers' knowledge needed for teaching.

\footnotetext{
Y. Li (ه)

Department of Teaching, Learning and Culture,

College of Education and Human Development,

Texas A\&M University,

College Station, TX 77843-4232, USA

e-mail: yepingli@tamu.edu
}

As direct reporting from TEDS-M, this issue contains papers that highlight different constructs used there to examine pre-service teachers' knowledge needed for teaching. In particular, teachers' knowledge needed for teaching is conceptualized as consisting of at least two essential components: mathematics content knowledge (MCK) and mathematics pedagogical content knowledge (MPCK) (e.g., Döhrmann, Kaiser, and Blömeke; Hsieh, Lin, and Wang; Senk et al.). Further specifications for MCK follow the assessment framework for mathematics content from the Trends in Mathematics and Science Studies (TIMSS; Mullis et al. 2007). It thus consists of four content subdomains (number and operations, algebra and functions, geometry and measurement, and data and chance) together with three cognitive subdomains (knowing, applying, and reasoning). The MPCK framework was developed based on a literature review, findings from a previous study, and critical reviews by international experts in the field. Three subdomains were identified and used in TEDS-M: mathematics curricular knowledge, knowledge of planning for mathematics teaching and learning, and knowledge of enacting teaching.

Such a conceptualization of teachers' mathematics knowledge needed for teaching had never before been developed and used in a large-scale cross-national study. It represents a big step in coming to a general understanding of different content knowledge components important to mathematics teachers' competence. Based on this knowledge conceptualization, differences in pre-service teachers' MCK and MPCK were found both within and across programs and systems (e.g., Senk et al.; Schmidt, Houang, and Cogan). Taking a step further, TEDS-M researchers also identified anchor points for both the MCK scale and the MPCK scale to describe qualitative characteristics of knowledge for teaching mathematics (Senk et al.). 
Besides MCK and MPCK, general pedagogical knowledge (GPK) is also discussed and accepted in conceptualizing teachers' knowledge needed for teaching (e.g., Shulman 1986, 1987). Although TEDS-M had a focus on the content-related knowledge in the common international tests, a national option was used for assessing pre-service mathematics teachers' GPK. Three education systems (Germany, Taiwan, and the United States) decided to choose this assessment option (König and Blömeke). According to König and Blömeke, a task-based conceptualization of GPK was used to specify four dimensions of GPK (structure, motivation/classroom management, adaptivity, and assessment) together with three performance requirements (recall, understand/analyze, generate) in answering different GPK test items. It seems that the conceptualization of GPK took a perspective different from conceptualizing MCK and MPCK in TEDS-M. Although possible connections among these three knowledge components are not clear, the inclusion of GPK highlighted an important step in understanding and examining the different knowledge components needed for teaching.

2. This thematic issue examines and compares noncognitive factors that contribute to pre-service teachers' performance.

Cognitive components are certainly important in conceptualizing and assessing what pre-service teachers need to have for teaching, but so are non-cognitive components. In fact, beliefs about the nature of mathematics were included as an essential component of teacher professional competence in TEDS-M (Felbrich, Kaiser, and Schmotz). A two-dimensional structure was used to represent the dynamic (mathematics as a process of inquiry) and the static (mathematics as a set of rules and procedures) perspectives about the nature of mathematics. Felbrich, Kaiser, and Schmotz not only reported the results obtained from TEDS-M but also tried to make connections with the cultural orientations (i.e., individualistic or collectivist orientation) embedded in participating education systems. While such cultural connections are not conclusive, based on their analyses the results do suggest likely patterns of pre-service teachers' belief profiles with their cultural orientation across different education systems.

3. This thematic issue includes papers that connect teacher preparation policies and program practices with pre-service teachers' performance in knowledge tests.

To make further use of the results concerning pre-service teachers' knowledge needed for teaching, TEDS-M aimed to examine and understand possible influences of national policy and program practices on the outcomes of mathematics teacher preparation. To make such connections, the thematic issue includes two papers that look at the cases of Singapore (Wong, Boey, Lim-Teo, and Dindyal) and the United States (Schmidt, Houang, and Cogan).

Wong, Boey, Lim-Teo, and Dindyal provided a detailed description of the primary mathematics teacher preparation system and its changes in Singapore. Through reflecting on Singapore's policy and practices, the researchers highlighted the importance of both the recruitment and training provided to pre-service mathematics teachers. Given Singapore pre-service teachers' high performance in TEDS-M, their description and reflections about teacher preparation policy and practices are certainly important for others to learn. At the same time, possible connections between pre-service teachers' performance in knowledge assessment in TEDS-M and their opportunity-to-learn (OTL) measures in Singapore could not be established easily. Apart from certain correlations between pre-service teachers' OTL in tertiary level mathematics and their performance in MCK and MPCK, the researchers did not find other possible connections (e.g., pre-service teachers' perceptions of their training program effectiveness were not linked to their performance in MCK and MPCK). The results suggest the difficulty of making direct connections between teachers' performance and their program studies even within an education system.

Schmidt, Houang, and Cogan took a close look at the case of the United States, a decentralized education system that is opposite to the centralized education in Singapore. Given the dramatic variations in recruitment/selection and program preparation of pre-service primary teachers in the United States, the researchers examined possible connections between these two factors and pre-service primary teachers' performance. Their analyses led to the findings that both "recruiting/selecting more mathematically able students" and "providing key mathematics and mathematics pedagogy OTL courses" have important connections with pre-service primary teachers' MCK and MPCK.

4. This thematic issue contains a balanced set of papers that examine pre-service teachers' performance and teacher education practices both within and across education systems.

Another important feature of this thematic issue is its selection and inclusion of a well-balanced set of papers. It contains those papers that focused on pre-service teachers' performance in knowledge tests within an education system (Hsieh, Lin, and Wang; Schmidt, Houang, and Cogan; Wong, Boey, Lim-Teo, and Dindyal) as well as across different education systems (Blömeke and Kaiser; Döhrmann, Kaiser, and Blömeke; Felbrich, Kaiser, and Schmotz; König and Blömeke; Senk et al.). However, the papers took different foci in terms of content, with several 
on the conceptualization of teachers' knowledge needed for teaching (Döhrmann, Kaiser, and Blömeke; Hsieh, Lin, and Wang; König and Blömeke; Senk et al.) and others on policy and program practices related to pre-service teachers' performance (e.g., Blömeke and Kaiser; Schmidt, Houang, and Cogan; Wong, Boey, Lim-Teo, and Dindyal). The combination of these papers reflects the issue's editors' thoughtful consideration and provides rich information from the TEDS-M study and beyond.

Just as with many other good collections of papers, my reading of this thematic issue also inspired me to think more about what I do not know but want to learn. In the spirit of generating more discussion and possible research efforts in the future, I list four questions below for consideration.

1. Is mathematics teachers' knowledge needed for teaching universal or system-cultural specific?

Although conceptualizing and examining teachers' knowledge needed for teaching has been a topic of many studies (e.g., Even and Ball 2009; Hill et al. 2007; Shulman 1986), it has been explored mainly within education systems and not in an international context. Nevertheless, cross-national studies have revealed that mathematics teachers from different educational systems differ in terms of what they know and how well they know about school mathematics (e.g., Li et al. 2008; Ma 1999). In general, the TEDS-M study took a similar approach in examining what pre-service teachers may know and how well they know in terms of selected components of knowledge important for teaching. Researchers (Döhrmann, Kaiser, and Blömeke; Hsieh, Lin, and Wang) argued that the assessment of these selected components are likely to have important limitations when looking at the results across different education systems in TEDS-M.

The conceptualization of teachers' mathematics knowledge needed for teaching should relate to what mathematics teachers may need to do for and in teaching, as well as what is important for teachers in order to carry out culturally valued mathematics instruction in different education systems. Because teaching is a cultural activity, it is reasonable to assume that teachers in different education systems have different kinds of knowledge and skills. For example, China has a centralized education system and Chinese teachers may need different curriculum knowledge compared to their counterparts in the United States. Yet, following prescribed content closely in a mathematics textbook in China does not mean that Chinese teachers need to have less curriculum knowledge. In fact, Chinese teachers spent a lot of time studying textbooks in depth, and this practice is viewed by Chinese teachers as the main approach for gaining the mathematics knowledge needed for teaching (e.g., Ma 1999). A recent study illustrated what a Chinese teacher did in transforming textbook content for classroom instruction through identifying and organizing the important points of teaching and the difficult points of teaching ( $\mathrm{Li}$ and $\mathrm{Li} 2009$ ). Such activity is an important feature of mathematics curriculum and instruction in China but not in the United States (Silver 2009).

The difficulty in assessing what teachers need to know for teaching resides in the challenge of conceptualizing the nature of teacher expertise in an international context. Although recent studies have helped to reveal different perspectives through viewing expert teachers and their expertise in different education systems, conceptualizing and examining mathematics teacher expertise in an international context remains a great challenge ( $\mathrm{Li}$ and Kaiser 2011). Further efforts are needed to examine the nature of teacher expertise valued in different education systems, and to identify common knowledge elements that are important for teachers across education systems as well as those cultural-specific manifestations of common knowledge elements and unique elements. Moreover, examination of pre-service teachers' knowledge needed for teaching may call for assessments different from those of in-service teachers (e.g., Li and Kulm 2008).

2. Are teachers' knowledge needed for teaching and their beliefs connected as essential components of teacher expertise?

In the TEDS-M study, pre-service teachers' beliefs about the nature of mathematics were also viewed as an important component of teacher competence/expertise. However, it is unclear whether pre-service teachers' knowledge needed for teaching may be pieced together with their beliefs or whether they should be treated as two independent components of teacher expertise. Further research is needed to examine possible relationships both within and across system-cultural contexts.

3. Can pre-service teachers' beliefs and their development be related to system policy and program practices?

The thematic issue includes papers that examine possible connections between teacher preparation policy and practices and program outcomes as measured by pre-service teachers' performance in knowledge tests (e.g., Schmidt, Houang, and Cogan; Wong, Boey, Lim-Teo, and Dindyal). Pre-service teachers' beliefs about the nature of mathematics are also examined in reference to the cultural orientation of different education systems (Felbrich, Kaiser, and Schmotz). However, it is unclear whether preservice teachers' beliefs are also influenced by system policy and program practices. The question is motivated 
by the intention of identifying possible approaches and practices that can lead to positive changes in pre-service teachers' beliefs about the nature of mathematics and mathematics teaching.

4. Can system policy and program practices be examined and compared for the purpose of learning and developing "best practices"?

Given the vast differences across these education systems included in TEDS-M, it is natural to ask this question. Regarding it positively, one could learn through reflecting on one's own system's policy and practices in light of those used in other education systems. However, teacher preparation programs have long been set up without systematic examination, but rather on experience-based judgments. An important part of the TEDS-M study was to collect teacher preparation program and curriculum information. In particular, Blömeke and Kaiser (this issue) examine profiles of OTL in primary teacher education and their relationship to cultural context and outcomes. There is no doubt that such analyses are clearly important to have, especially in relation to the assessment of pre-service teachers' knowledge. It remains unclear whether we may learn further about program structure and curricula that have been put in place for teacher preparation within and across education systems. Efforts are needed to explore further teacher preparation policy and practices that can improve the quality of teacher preparation programs.

In conclusion, I highly recommend this thematic issue to readers. The collection of papers has not only allowed me to learn much about the TEDS-M study and discover many insightful findings, but also inspired me to want to know more. Hopefully, this commentary paper can help generate further discussions about mathematics teacher preparation and its quality improvement in an international context.

\section{References}

Even, R., \& Ball, D. L. (Eds.). (2009). The Professional Education and Development of Teachers of Mathematics: The 15th ICMI Study. New ICMI Study Series, 11. New York, NY: Springer.
Hill, H. C., Sleep, L., Lewis, J., \& Ball, D. L. (2007). Assessing teachers' mathematical knowledge: What knowledge matters. In F. K. Lester Jr (Ed.), Second handbook of research on mathematics teaching and learning (pp. 111-156). Charlotte, NC: Information Age Publishing.

Leung, F. K. S., \& Li, Y. (Eds.) (2010). Reforms and issues in school mathematics in East Asia-Sharing and understanding mathematics education policies and practices. Rotterdam, The Netherlands: Sense Publishers.

Li, Y., \& Kaiser, G. (Eds.). (2011). Expertise in mathematics instruction: An international perspective. New York: Springer.

Li, Y., \& Kulm, G. (2008). Knowledge and confidence of pre-service mathematics teacher: The case of fraction division. ZDM-The International Journal on Mathematics Education, 40, 833-843.

Li, Y., \& Li, J. (2009). Mathematics classroom instruction excellence through the platform of teaching contests. ZDM-The International Journal on Mathematics Education, 41, 263-277.

Li, Y., Ma, Y., \& Pang, J. (2008). Mathematical preparation of prospective elementary teachers. In P. Sullivan \& T. Wood (Eds.), International handbook of mathematics teacher education: Knowledge and beliefs in mathematics teaching and teaching development (pp. 37-62). Rotterdam, The Netherlands: Sense Publishers.

Ma, L. (1999). Knowing and teaching elementary mathematics: Teachers' understanding of fundamental mathematics in China and the United States. Mahwah, NJ: Lawrence Erlbaum Associates.

Mullis, I. V. S., Martin, M. O., Ruddock, G. J., O’Sullivan, C. Y., Arora, A., \& Erberber, E. (2007). TIMSS 2007 assessment frameworks. Chestnut Hill, MA: Boston College.

Shulman, L. S. (1986). Those who understand: Knowledge growth in teaching. Educational Researcher, 15(2), 4-14.

Shulman, L. S. (1987). Knowledge and teaching: Foundations of the new reform. Harvard Educational Research, 57, 1-22.

Silver, E. A. (2009). Cross-national comparisons of mathematics curriculum materials: what might we learn? ZDM-The International Journal on Mathematics Education, 41, 827-832.

Sowder, J. T. (2007). The mathematical education and development of teachers. In F. K. Lester Jr (Ed.), Second handbook of research on mathematics teaching and learning (pp. 157-223). Charlotte, NC: Information Age Publishing.

Wilson, S. M., Floden, R. E., \& Ferrini-Mundy, J. (2001). Teacher preparation research: Current knowledge, gaps and recommendations. A research report prepared for the US Department of Education by the Center for the Study of Teaching and Policy in collaboration with Michigan State University. http://depts. washington.edu/ctpmail/PDFs/TeacherPrep-WFFM-02-2001.pdf. Accessed 3 May 2012. 